\title{
PERANCANGAN SISTEM INFORMASI KELUHAN PASIEN PADA PUSKESMAS KELURAHAN PASEBAN
}

\author{
Ito Riris Immasari ${ }^{1}$, Sofia Dara Sari ${ }^{2}$ \\ Sekolah Tinggi Manajemen Informatika dan Komputer Jayakarta \\ Jl. Salemba I No.10, RT.4/RW.6, Kenari, Senen, Jakarta Pusat, Indonesia \\ itor_immasari@stmik.jayakaarta.ac.id, sofia_dr@gmail.com
}

\begin{abstract}
ABSTRAK: Keluhan pasien merupakan hal sangat penting untuk dipelajari bagi pelayanan yang diberikan puskesmas agar semakin menyenangkan pasien. Keluhan pasien jika tidak ditangani dengan serius maka akan berdampak buruk pada citra puskesmas. Puskesmas kelurahan paseban saat ini masih menggunaan cara manual dalam proses pengisin serta rekap hasil keluhan pasih, hal itu membuat admin sering merasa kesulitan dalam malakukan proses rekap hasil keluhan pasien dan tidak menutup kemungkinan admin sering mengalami kesalahan input data, cara ini dianggap tidak efektif dan tidak effisien sehinnga perlu dibuat sebuah system yang dapat membantu admin dalam membantu melakukan proses rekap hasil keluhan serta mempermudah admin mengetahui sarana dan prasarana apa yang harus segera diperbaiki menjadi lebih efektif dan effisien dengan bantuan sistem berbasis web yang terkomputerisasi.
\end{abstract}

Kata Kunci : keluhan pasien, web, waterfall

Abstract: Patient complaints are very important things to learn for the services provided by the puskesmas to make patients more comfortable. If patient complaints are not taken seriously, it will have a bad impact on the image of the puskesmas. The Paseban sub-district health center is currently still using the manual method in the process of filling out and recapitulating the results of pasih complaints, it makes admins often find it difficult to process the recapitulation of patient complaints and does not rule out the possibility that admins often experience data input errors, this method is considered ineffective and not efficient so it is necessary to create a system that can assist admins in helping to process the recap of the results of complaints and make it easier for admins to know what facilities and infrastructure must be repaired to be more effective and efficient with the help of a computerized web-based system.

Keywords: complaint, web, waterfall

\section{PENDAHULUAN}

Salah satu bentuk upaya pemerintah dalam menyelenggarakan kesehatan kepada masyarakat maka di tiap kecamatan dengan dibangunnya Pusat Kesehatan Masyarakat atau disebut Puskesmas. Puskesmas

This work is licensed under a Creative Commons Attribution-NonCommercial-ShareAlike 4.0 International License. 
Kelurahan Paseban merupakan unit pelaksanaan teknis Kesehatan di bawah Supervisi Dinas Kesehatan. Secara umum memberikan Pelayanan Preventif ( Upaya Pencegahan ), Promotif ( Peningkatan Kesehatan ), Kuratif ( Pengobatan )sampai dengan Rehabilitatif ( Pemulihan Kesehatan )baik melalui upaya Kesehatan Perorangan ( UKP ) atau Upaya Kesehatan Masyarakat ( UKM ). Puskesmas Kelurahan Paseban dapat memberikan pelayanan yang baik tentunya selalu diusahakan adanya peningkatan kualitas pelayanan rawat jalan.

Ketidak puasan pelayanan dapat berasal dari Sarana dan Prasarana seperti kebersihan ruang tunggu, kebersihan ruang perawatan, dan kelalaian petugas dalam menangani keluhan pasien, hal ini dikarenakan daya tampung dari Puskesmas ini sangat minim. Tidak bisa dipungkiri daya tampung berdampak pada antrian pasien yang akan mendapatkan pelayanan pada Puskesmas, sehingga kemungkinan untuk terjadi nepotisme dalam palayanan kesehatan sangat mungkin untuk terjadi. Permasalahan yang kemungkinan terjadi adalah membludaknya pasien yang akan datang berobat dan terlalu lamanya peroses pendaftaran, pemeriksaan dokter poli dan Farmasi. Hal tersebut kemungkinan menjadi pengalaman yang mengecewakan bagi para pasien yang berobat di Puskesmas Kelurahan Paseban.

Puskesmas dapat mengukur kualitas pelayanan dari para pasien melalui umpan balik yang masih menggunakan teknik manual mengalami kendala dan kurang efektif, dengan adanya perkembangan dan pemanfaatan terutama dalam menggunakan system berbasis web Puskesmas dapat mengukur peningkatan kualitas pelayanan.

\section{METODE DAN MATERI}

\subsection{MATERI}

\subsubsection{Puskesmas}

Depkes RI (2004), Puskesmas adalah unit pelaksana teknis Dinas Kesehatan Kabupaten/Kota yang bertanggung jawab menyelenggarakan pembangunan kesehatan di suatu wilayah kesehatan. Menurut Ilham Akhsanu Ridho (2008:143) Puskesmas adalah suatu unit organisasi yang bergerak dalam bidang pelayanan kesehatan yang berada di garda terdepan dan mempunyai misi sebagai pusat pengembangan pelayanan kesehatan, yang melaksanakan pembinaan dan pelayanan kesehatan secara menyeluruh dan terpadu untuk masyarakat di suatu wilayah kerja tertentu yang telah ditentukan secara mandiri dalam menentukan kegiatan pelayanan namun tidak mencakup aspek pembiayaan.

Puskesmas merupakan kesatuan organisasi fungsional yang menyelenggarakan upaya kesehatan yang bersifat menyeluruh, terpadu, merata dapat diterima dan terjangkau oleh masyarakat dengan peran serta aktif masyarakat dan menggunakan hasil pengembangan ilmu pengetahuan dan teknologi tepat guna, dengan biaya yang dapat dipikul oleh pemerintah dan masyarakat luas guna mencapai derajat kesehatan yang optimal, tanpa mengabaikan mutu pelayanan kepada perorangan (Depkes, 2009).

\subsubsection{Pasien}

Dikutip dari Wikipedia, pasien atau pesakit adalah orang yang menerima perawatan medis. Seringkali pasien menderita penyakit atau cidera dan memerlukan bantuan dokter untuk memulihkannya.

\section{This work is licensed under a Creative Commons Attribution-NonCommercial-ShareAlike 4.0}


TRIDHARMADIMAS: Jurnal Pengabdian Kepada Masyarakat Jayakarta

http://journal.stmikjayakarta.ac.id/index.php/tridharmadimas

EmaiL: info@ @stmik.jayakarta.ac.id , tridharmadimas.jayakarta@gmail.com

DOI : 10.52362/tridharmadimas.v1i2.648 /halaman : 86-101

E-ISSN: 2798-8295 (Online), P-ISSN: 2798-8554 (Print) Vol. 1, No.2, Desember 2021

Kata pasien dari bahasa Indonesia analog dengan kata patient dari bahasa Inggris yang artinya sabar. Patient diturunkan dari bahasa Latin yaitu patiens yang memiliki kesamaan arti dengan kata kerja pati yang artinya "menderita".

Menurut Peraturan Menteri Kesehatan Republik Indonesia Nomor 269/Menkes/Per/III/2008 Pasien adalah setiap orang yang melakukan konsultasi masalah kesehatan untuk memperoleh pelayanan kesehatan yang diperlukan baik secara langsung maupun tidak langsung kepada dokter atau dokter gigi.

\subsubsection{Sistem}

Menurut (Prawiro, 2018), sistem adalah suatu kesatuan, baik obyek nyata atau abstrak yang terdiri dari berbagai komponen atau unsur yang saling berkaitan, saling tergantung, saling mendukung, dan secara keseluruhan bersatu dalam satu kesatuan untuk mencapai tujuan tertentu secara efektif dan efisien.

Istilah "sistem" sering digunakan dalam berbagai bidang, sehingga maknanya akan berbeda-beda sesuai dengan bidang yang dibahas. Namun, secara umum kata "sistem" mengacu pada sekumpulan benda yang saling memiliki keterkaitan satu sama lainnya.

\subsubsection{Informasi}

Menurut (Putra, 2020), Informasi dibutuhkan oleh setiap orang, entah itu untuk memperbaharui pengetahuan, bahan beropini atau dasar dalam membuat keputusan. Konsep dasar informasi tak dapat dilepaskan dari definisi atau pengertian informasi, yaitu hasil pengolahan data menjadi bentuk yang berguna bagi penerimanya. Jadi, sumber informasi adalah data. Data adalah kenyataan yang menggambarkan peristiwa yang terjadi pada saat tertentu.

Informasi juga memiliki siklus. Bahan mentah berupa data diolah dengan metode tertentu untuk menghasilkan informasi. Informasi tersebut disampaikan, lalu digunakan oleh si penerima untuk membuat keputusan atau melakukan tindakan yang akan menghasilkan data baru lagi.

\subsubsection{Sistem Informasi}

Menurut (Robith, 2021), Definisi dari sistem informasi (SI) secara umum adalah suatu sistem yang mengkombinasikan antara aktivitas manusia dan penggunaan teknologi untuk mendukung manajemen dan kegiatan operasional. Dimana, hal tersebut merujuk pada sebuah hubungan yang tercipta berdasarkan interaksi manusia, data, informasi, teknologi, dan algoritma.

Penggunaan dari SI sendiri ditujukan untuk mengolah berbagai informasi yang dikelola oleh setiap perusahaan atau organisasi, sehingga sumber daya atau resources yang dibutuhkan tidak terlalu besar dan dapat mempersingkat waktu penanganan proses. Selain itu, data yang dikelola juga dapat digunakan kapan saja dan dimana saja, serta mampu mempersingkat birokrasi yang ada.

Tujuan dari pengembangan sistem informasi adalah untuk menghasilkan sebuah produk yang berisi kumpulan informasi. Sebuah sistem tentunya melibatkan berbagai jenis dan tipe data yang mampu diolah agar dapat ditampilkan dengan mudah kepada pengguna (user).

This work is licensed under a Creative Commons Attribution-NonCommercial-ShareAlike 4.0

International License. 


\subsection{METODE.}

Metodelogi yang digunakan perlu membuat sistem ini dengan menggunakan model Waterfall. Model Waterfall digambarkan secara garis besar sebagai berikut :

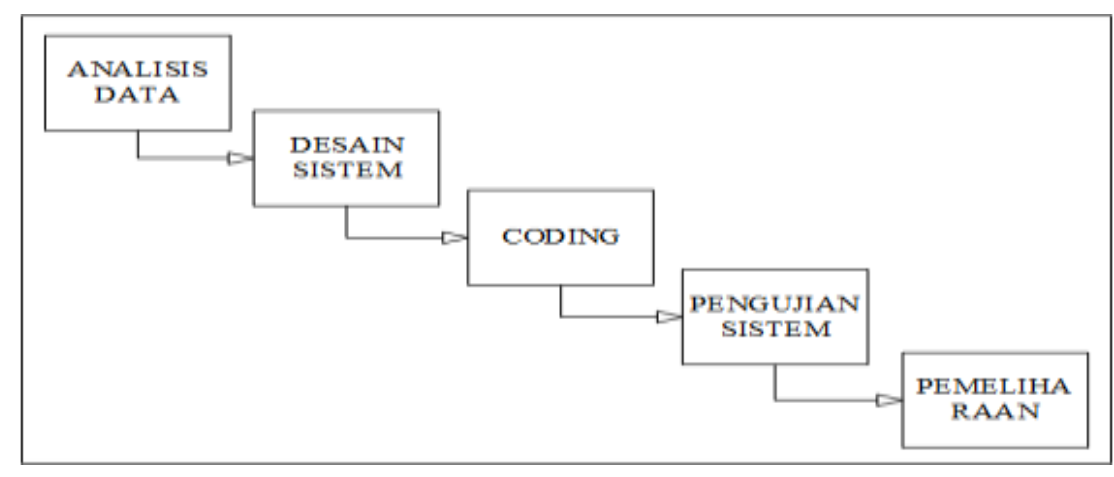

Gambar 1

Model Waterfall

Berikut adalah perencanaan sistem yang digunakan menggunakan metode Waterfall yaitu:

1. Analisis Data

Pada proses menganalisis kebutuhan data melalui hasil wawancara yang dilakukan oleh penulis kepada pihak-pihak terkait di Puskesmas Kel. Paseban yang nantinya akan dijadikan referensi untuk merancang sistem.

2. Desain Sistem.

Melakukan desain sistem yang akan di bangun sesuai dengan analisis data yang telah dilakukan yang kemudian akan dituangkan dalam bentuk rancangan flowchart, class diagram, uml serta layout dari sistem baru yang akan di rancang.

3. Coding

Setelah selesai melakukan desain sistem, maka selanjutnya mulai melakukan coding yaitu proses menterjemahakan dari bahasa mesin menjadi bahasa yang mudah di mengerti oleh manusia sehingga sistem dapat digunakan dengan mudah.

4. Pengujian Sistem

Setelah proses coding selesai, maka sistem yang telah di buat akan di uji, hal ini bertujuan mengetahui sejauh mana tingkat kefektifan dari sistem yang baru serta untuk mengetahu sejauh mana keefektifan dari sistem yang baru ini.

5. Pemeliharaan 
TRIDHARMADIMAS: Jurnal Pengabdian Kepada Masyarakat Jayakarta

http://journal.stmikjayakarta.ac.id/index.php/tridharmadimas

EmaiL: info@stmik.jayakarta.ac.id , tridharmadimas.jayakarta@gmail.com

DOI : 10.52362/tridharmadimas.v1i2.648 /halaman : 86-101

E-ISSN: 2798-8295 (Online), P-ISSN: 2798-8554 (Print) Vol. 1, No.2, Desember 2021

Apabila sistem dirasa sudah efektif dan sudah layak digunakan, maka sistem akan dilakukan pemeliharaan secara berkala oleh tim it, hal ini bertujuan agar sistem selalu mendapatkan maintenance secara rutin sehingga sistem akan menjadi lebih sempurna.

\section{PEMBAHASAN DAN HASIL}

\subsection{PEMBAHASAN}

\subsubsection{Flowchart sistem yang sedang berjalan}

Flowchat sistem yang sedang berjalan di Puskesmas Kel Paseban sabagai berikut, yaitu :

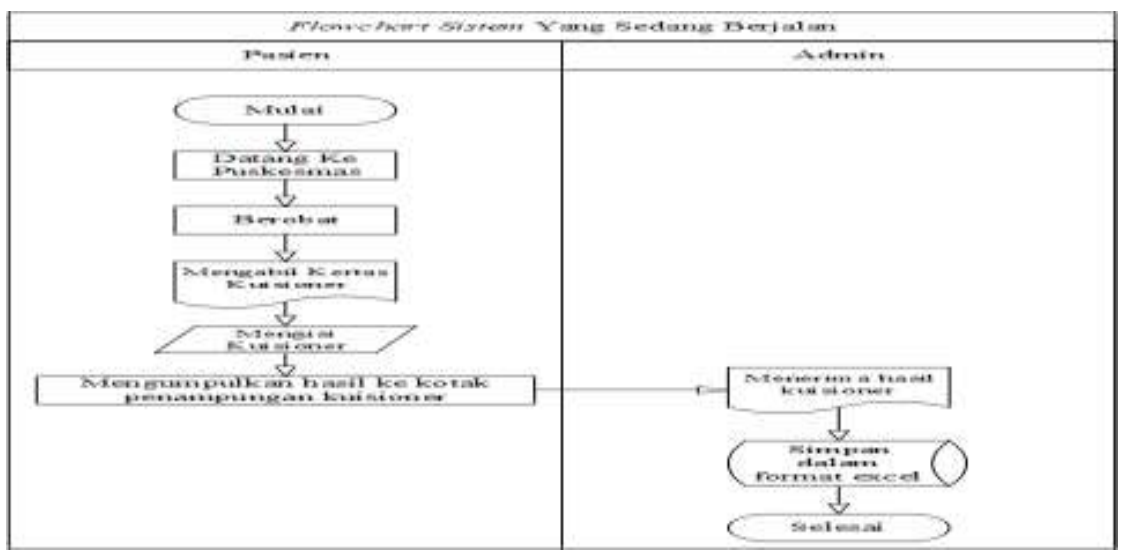

Gambar 2

Flowchart sistem yang sedang berjalan

Berdasarkan gambar 2 terdapat flowchart sistem yang sedang berjalan, hal pertama yang dilakukan oleh pasien adalah datang ke puskesmas, kemudian pasien berobat, setelah berobat maka pasien mengambil kertas kuisioner, setelah mengambil kertas kuisioner maka pasien mengisi kuisioner, lalu pasien mengumpulkan kertas hasil kuisioner ke kotak penampungan hasil kuisioner, Selanjutnya admin menerima hasil kuisioner dari kotak penampungan hasil kuisioner untuk di rekap menjadi format excel.

\subsubsection{Activity diagram sistem yang sedang berajalan}

Proses activity diagram sistem yang sedang berjalan di puskesmas keluraha paseban yaitu :

\section{(c) (1) (-) (2)}

This work is licensed under a Creative Commons Attribution-NonCommercial-ShareAlike 4.0 International License. 
EmaiL: info@stmik.jayakarta.ac.id , tridharmadimas.jayakarta@gmail.com

DOI : $10.52362 /$ tridharmadimas.v1i2.648 /halaman : 86-101

E-ISSN: 2798-8295 (Online), P-ISSN: 2798-8554 (Print) Vol. 1, No.2, Desember 2021

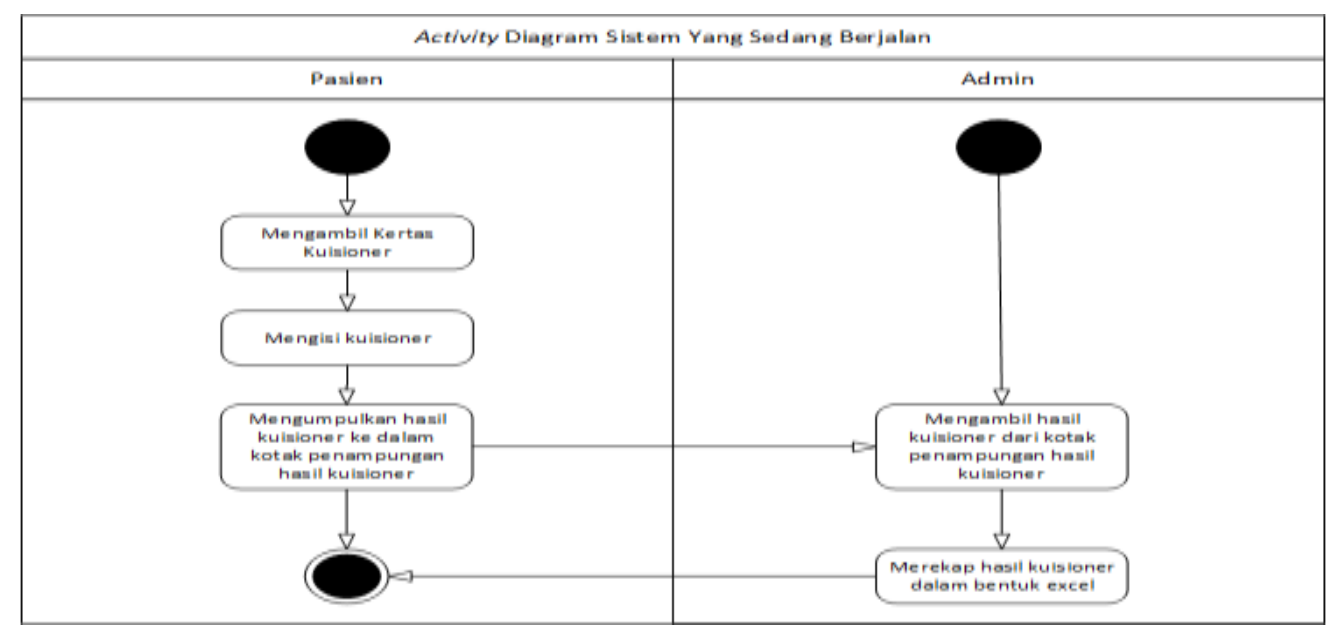

Gambar 3

Activity Diagram sistem yang sedang berjalan

Berdasarkan gambar 3. terdapat Activity diagram yang sedang berjalan, terdapat 2 aktor yaitu pasien dan admin, hal pertama yang dilakukan oleh pasien adalah mengambil kertas kuisioner dan mengisinya, setelah mengisi kuisioner selanjutnya pasien mengumpulkan hasil kuisioner kedalam kotak penampungan hasil kuisioner, lalu admin mengambil hail kuisioner dari kotak penampungan kemudian admin merekapnya menjadi dalam format excel.

\subsubsection{Use case diagram sistem yang sedang berjalan}

Use case diagram sistem yang sedang berjalan yang sedang berjalan menggunakan use case diagram sebagai berikut :

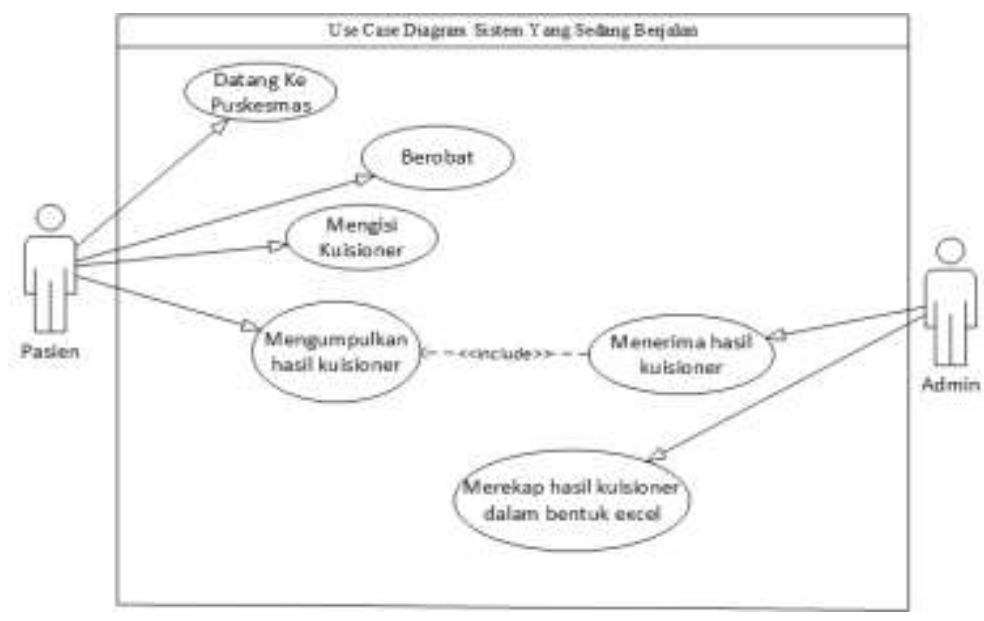

Gambar 4

Use Case Diagram sistem yang sedang berjalan

\section{(c) (i) (-)}

This work is licensed under a Creative Commons Attribution-NonCommercial-ShareAlike 4.0 International License. 
TRIDHARMADIMAS: Jurnal Pengabdian Kepada Masyarakat Jayakarta

http://journal.stmikjayakarta.ac.id/index.php/tridharmadimas

EmaiL: info@stmik.jayakarta.ac.id , tridharmadimas.jayakarta@gmail.com

DOI : 10.52362/tridharmadimas.v1i2.648/halaman : 86-101

E-ISSN: 2798-8295 (Online), P-ISSN: 2798-8554 (Print) Vol. 1, No.2, Desember 2021

Berdasarkan gambar 4 terdapat 2 (dua) aktor yaitu pasien dan admin, pasien wajib datang ke puskesma lalu berobat, setelah berobat mengisi kuisioner dan jika selesai mengumpulkan kuisoner pada kotak penampungan kuisioner, kemudian admin menerima hasil kuisioner dan merekapnya dalam format excel.

\subsubsection{Rancangan Tampilan Login}

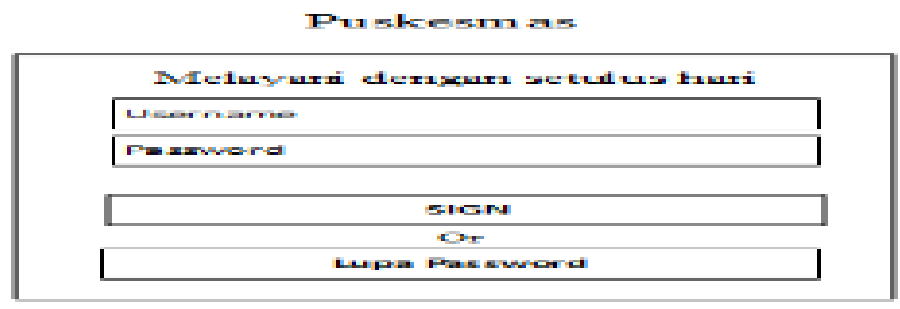

Gambar 5

Rancangan Tampilan Login

Berdasarkan gambar 5 terlihat sebuah rancangan tampilan login. Halaman login ini berfungsi sebagai akes agar admin bisa masuk kedalam dashboard aplikasi dengan cara memasukan username dan password kemudian menekan tombol sign.

\subsubsection{Rancangan Tampilan Dashboard Admin}

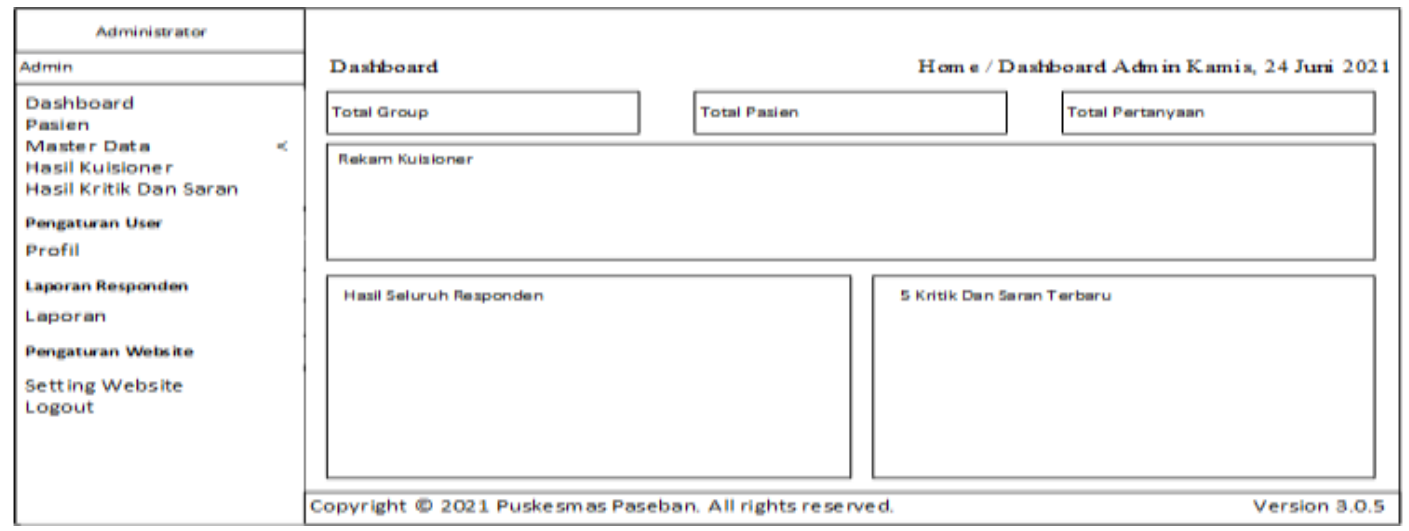

Gambar 6

Rancangan Tampilan Dashboard Admin

Berdasarkan gambar 6 terlihat sebuah rancangan tampilan dashboard admin, halaman ini merupakan tampilan utam setelah admin berhasil login, didalam halaman ini admin dapat memiliki fitur manajemen yaitu : manajemen pasien, manajemen group, manajemen pertanyaan, manajemen hasil kuisioner dan manajemen laporan.

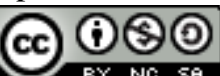

This work is licensed under a Creative Commons Attribution-NonCommercial-ShareAlike 4.0 International License. 
EmaiL: info@stmik.jayakarta.ac.id , tridharmadimas.jayakarta@gmail.com

DOI : 10.52362/tridharmadimas.v1i2.648 /halaman : 86-101

E-ISSN: 2798-8295 (Online), P-ISSN: 2798-8554 (Print) Vol. 1, No.2, Desember 2021

\subsubsection{Rancangan Tampilan Master Pasien}

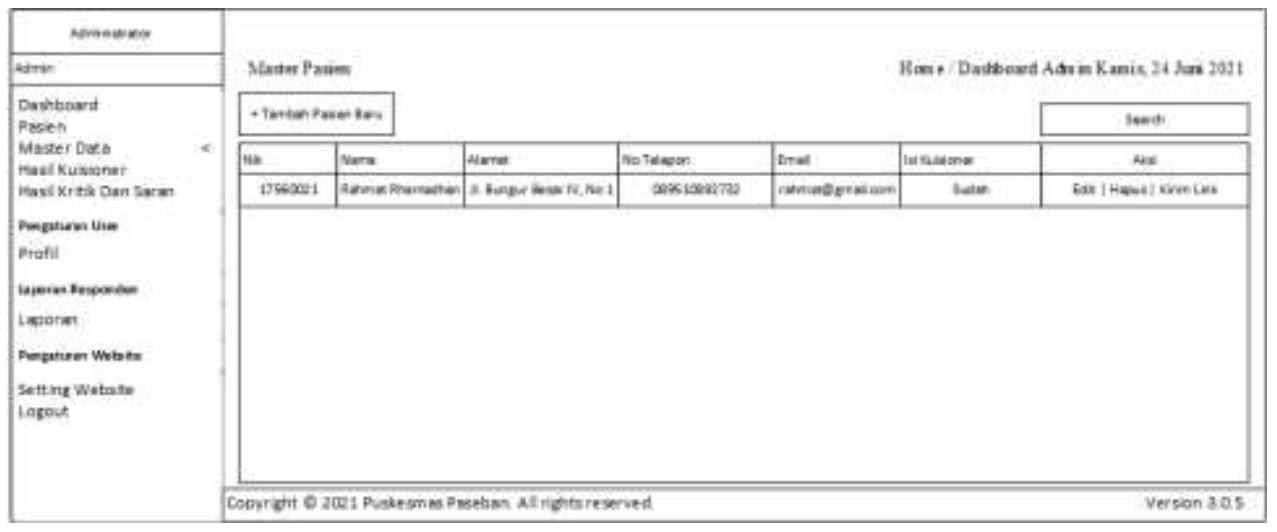

Gambar 7

Rancangan Tampilan Master Pasien

Berdasarkan gambar 7 terlihat sebuah rancangan tampilan master pasien, pada halaman ini berisi mengenai data pasien, didalam halaman ini, admin dapat melakukan manajemen data pasien serta mengirim link kuisioner kepada pasien.

\subsubsection{Rancangan Tampilan Master Group}

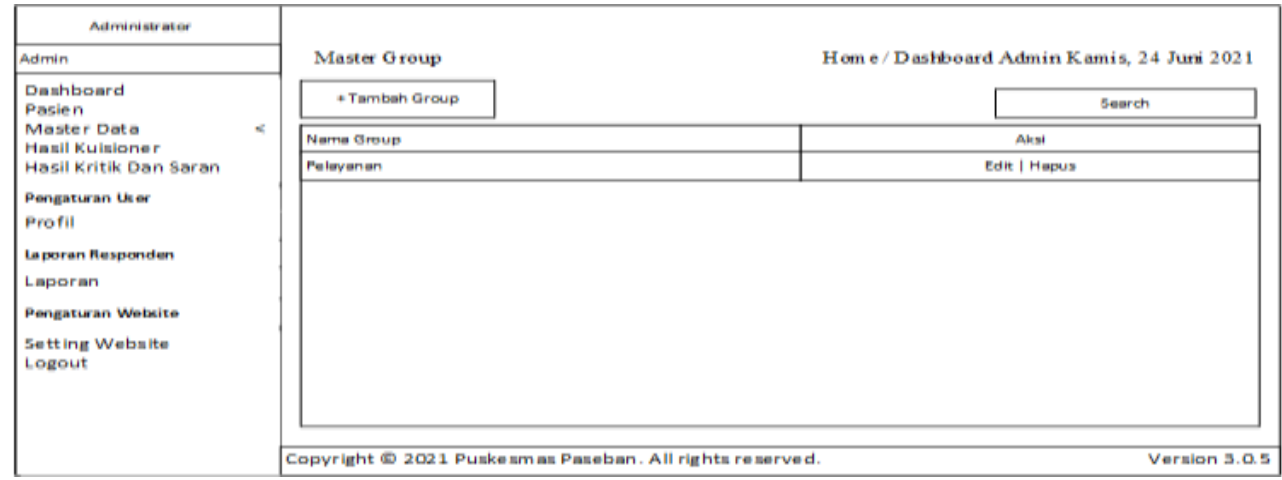

Gambar 8

Rancangan Tampilan Master Group

Berdasarkan gambar 8 terlihat sebuah rancangan tampilan master group, halaman ini berisi tentang data group pertanyaan kuisioner, didalam halaman ini, admin dapat memanajemen data group.

\section{c) (i) (3)(2)


EmaiL: info@stmik.jayakarta.ac.id , tridharmadimas.jayakarta@gmail.com

DOI : 10.52362/tridharmadimas.v1i2.648 /halaman : 86-101

E-ISSN: 2798-8295 (Online), P-ISSN: 2798-8554 (Print) Vol. 1, No.2, Desember 2021

\subsubsection{Rancangan Tampilan Master Pertanyaan}

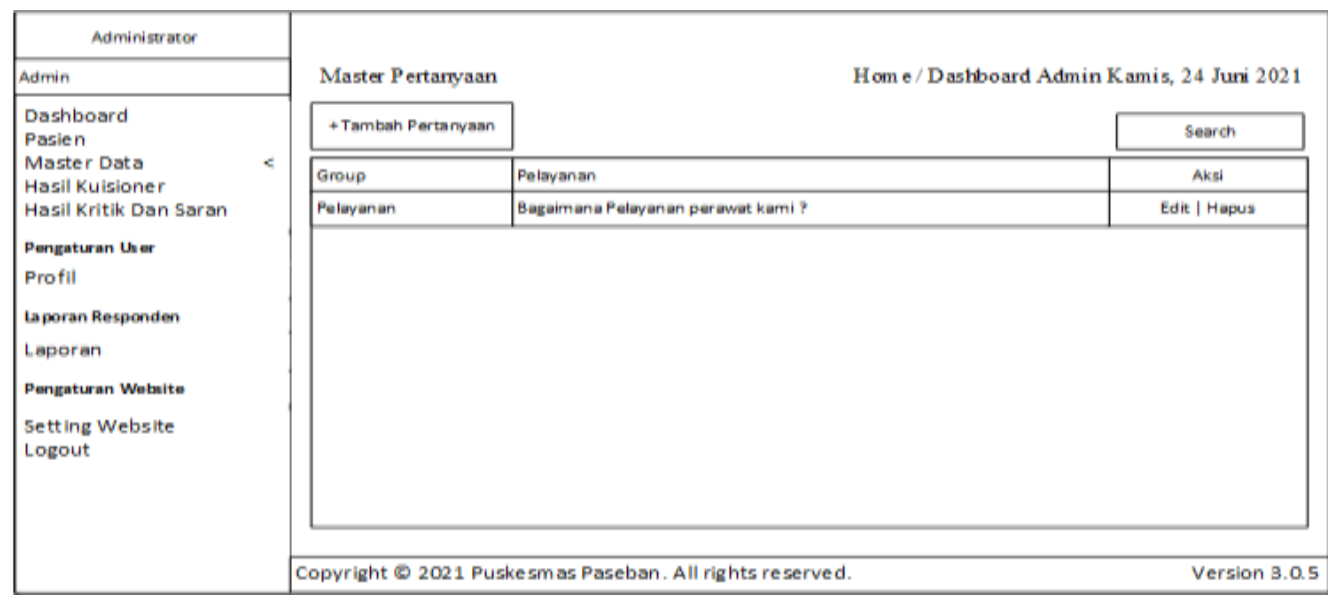

Gambar 9

Rancangan Tampilan Master Pertanyaan

Berdasarkan gambar 9 terlihat sebuah rancangan tampilan master pertanyaan, didalam halaman ini terdapat master data pertanyaan kuisioner, di halaman ini juga admin dapat melakukan manajemen data pertanyaan.

\subsubsection{Rancangan Tampilan Hasil Responden}

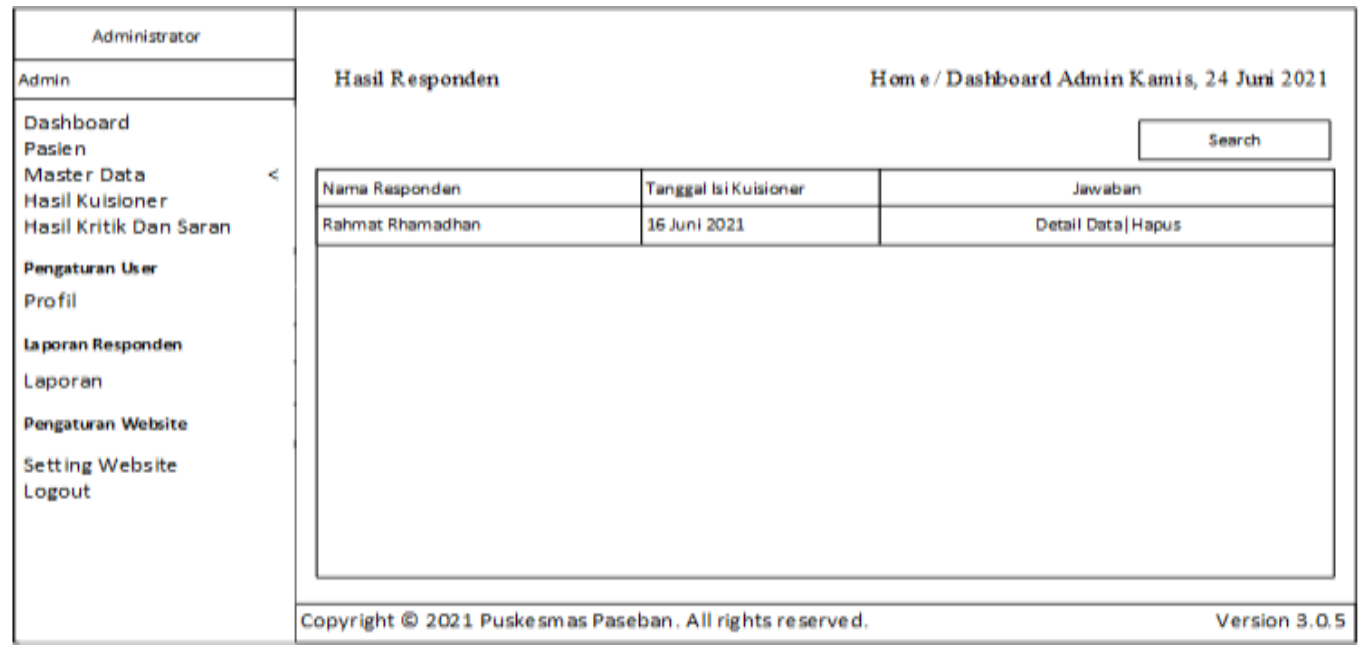

Gambar 10

Rancangan Tampilan Hasil Responden

Berdasarkan gambar 10 terlihat sebuah rancangan tampilan hasil responden, didalam halaman ini berisi master data hasil responden, didalam halaman ini juga, admin dapat melihat dan menghapus data hasil responden.

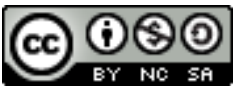

This work is licensed under a Creative Commons Attribution-NonCommercial-ShareAlike 4.0 International License. 
TRIDHARMADIMAS: Jurnal Pengabdian Kepada Masyarakat Jayakarta

http://journal.stmikjayakarta.ac.id/index.php/tridharmadimas

EmaiL: info@stmik.jayakarta.ac.id , tridharmadimas.jayakarta@gmail.com

DOI : $10.52362 /$ tridharmadimas.v1i2.648 /halaman : 86-101

E-ISSN: 2798-8295 (Online), P-ISSN: 2798-8554 (Print) Vol. 1, No.2, Desember 2021

\subsubsection{Rancangan Tampilan Master Kuisioner}

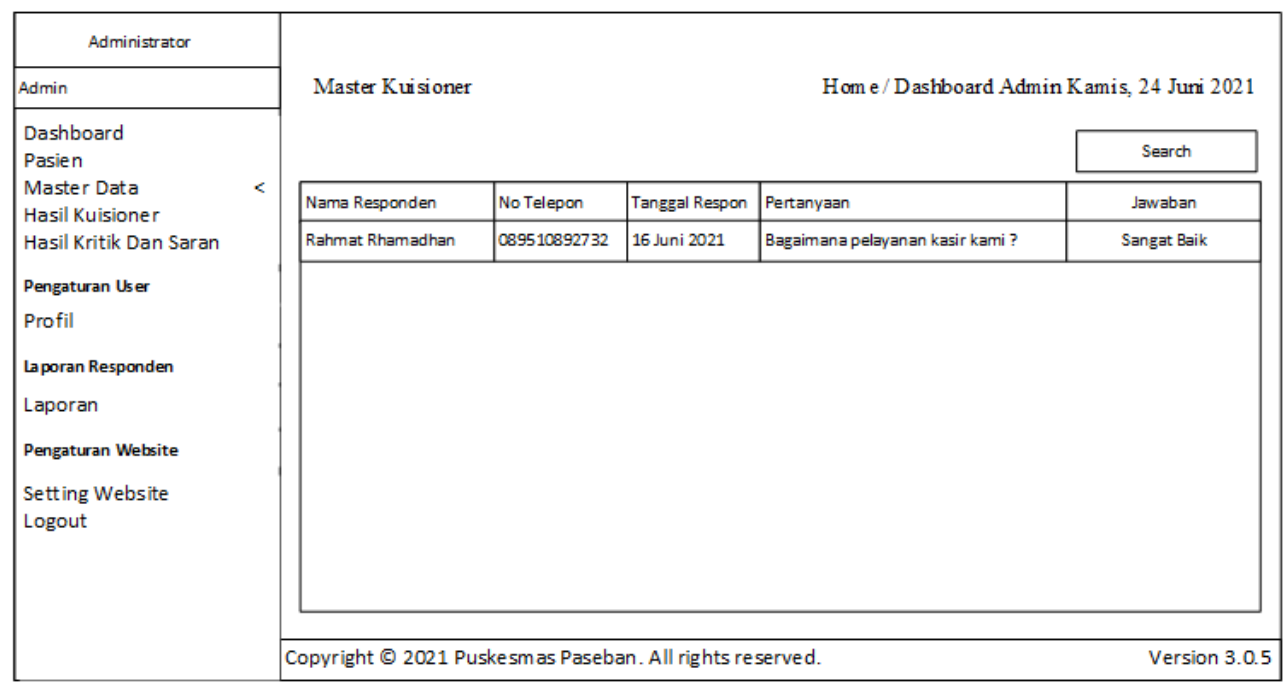

Gambar 11

Rancangan Tampilan Master Kuisioner

Berdasarkan gambar 11 terlihat sebuah rancangan tampilan master hasil kuisioner. Didalam halaman ini berisi tentang hasil seluruh kuisioner yang telah di isi oleh pasien.

\subsubsection{Rancangan Tampilan Master Kritik Saran}

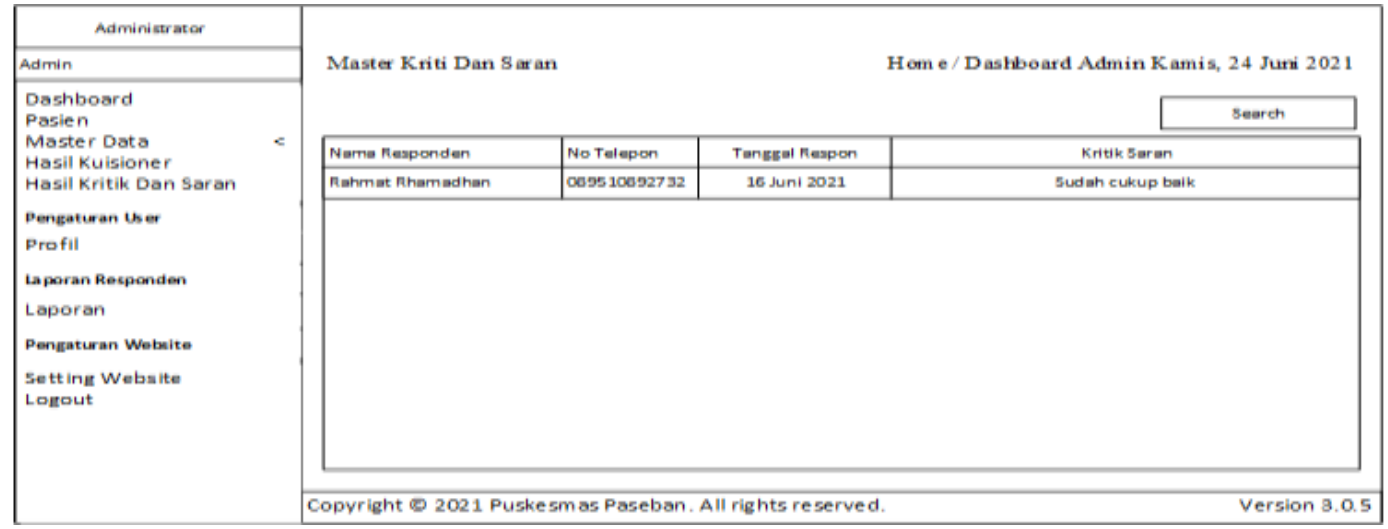

Gambar 12

Rancangan Tampilan Master Kritik Saran

Berdasarkan gambar 12 terlihat sebuah rancangan tampilan kritik dan saran. Pada halaman ini berisi tentang master data kritik dan saran yang telah diisi oleh pasien.

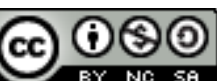

This work is licensed under a Creative Commons Attribution-NonCommercial-ShareAlike 4.0 International License. 
TRIDHARMADIMAS: Jurnal Pengabdian Kepada Masyarakat Jayakarta

http://journal.stmikjayakarta.ac.id/index.php/tridharmadimas

EmaiL: info@stmik.jayakarta.ac.id , tridharmadimas.jayakarta@gmail.com

DOI : $10.52362 /$ tridharmadimas.v1i2.648 /halaman : 86-101

E-ISSN: 2798-8295 (Online), P-ISSN: 2798-8554 (Print) Vol. 1, No.2, Desember 2021

\subsubsection{Rancangan Tampilan Mengisi Kuisioner}

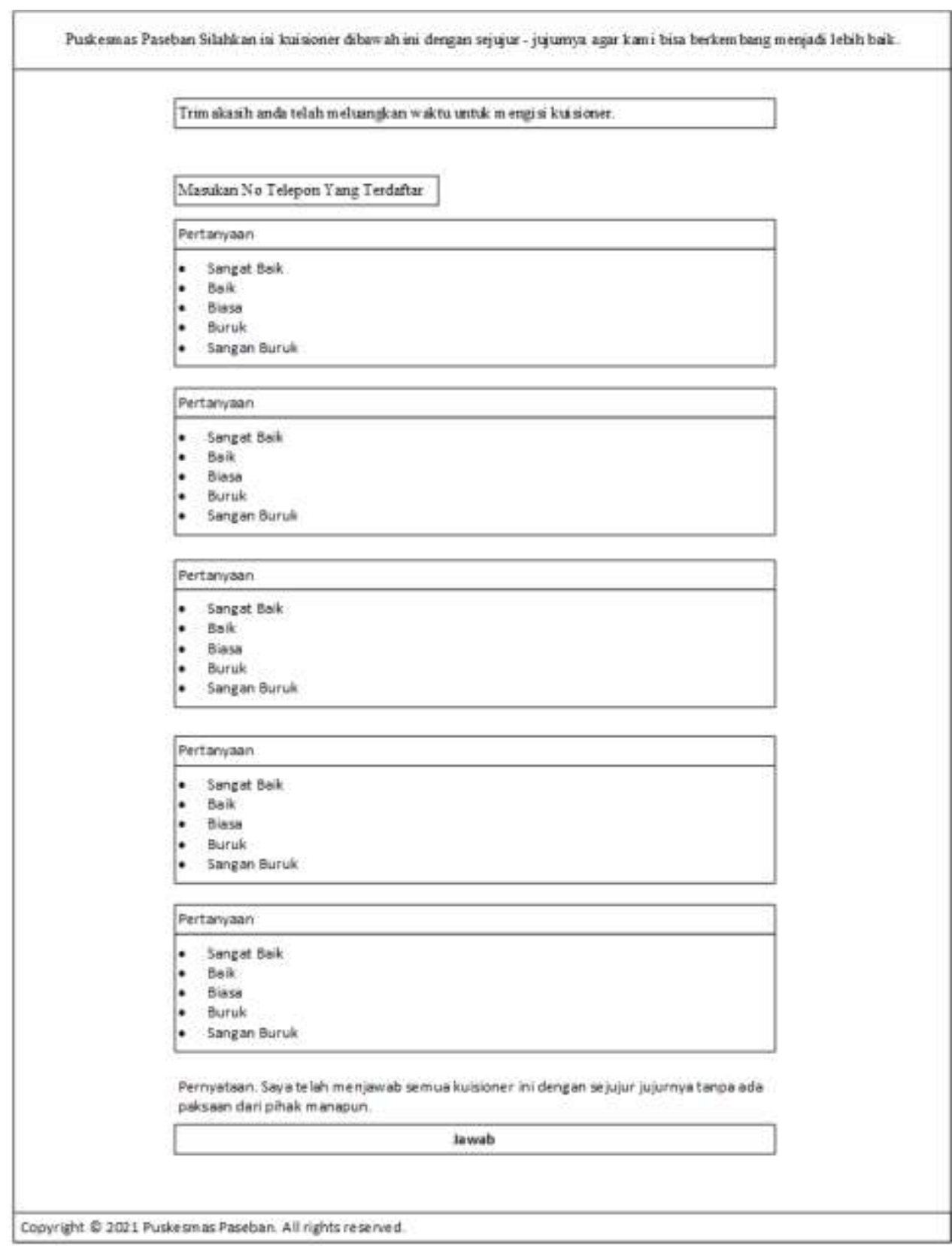

Gambar 13

Rancangan Tampilan Mengisi Kuisioner

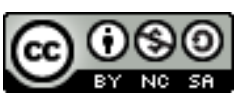

This work is licensed under a Creative Commons Attribution-NonCommercial-ShareAlike 4.0 International License. 
TRIDHARMADIMAS: Jurnal Pengabdian Kepada Masyarakat Jayakarta

http://journal.stmikjayakarta.ac.id/index.php/tridharmadimas

EmaiL: info@stmik.jayakarta.ac.id , tridharmadimas.jayakarta@gmail.com

DOI : 10.52362/tridharmadimas.v1i2.648 /halaman : 86-101

E-ISSN: 2798-8295 (Online), P-ISSN: 2798-8554 (Print) Vol. 1, No.2, Desember 2021

Berdasarkan gambar 13 terlihat rancangan tampilan mengisi kuisioner yang wajib di isi oleh pasien, didalamnya terdapa field yang wajib di isi oleh pasien.

\subsection{HASIL}

\subsubsection{Layout Login}

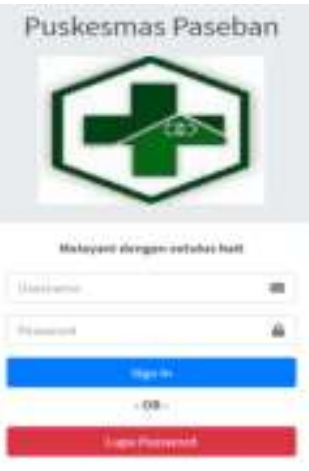

Gambar 14

Layout Login

Berdasarkan gambar 14 terlihat sebuah layout login. Halaman login ini berfungsi sebagai akes agar admin bisa masuk kedalam dashboard aplikasi dengan cara memasukan username dan password kemudian menekan tombol sign. 
TRIDHARMADIMAS: Jurnal Pengabdian Kepada Masyarakat Jayakarta

http://journal.stmikjayakarta.ac.id/index.php/tridharmadimas

EmaiL: info@stmik.jayakarta.ac.id , tridharmadimas.jayakarta@gmail.com

DOI : 10.52362/tridharmadimas.v1i2.648 /halaman : 86-101

E-ISSN: 2798-8295 (Online), P-ISSN: 2798-8554 (Print) Vol. 1, No.2, Desember 2021

\subsubsection{Layout Mengisi Kuisioner}

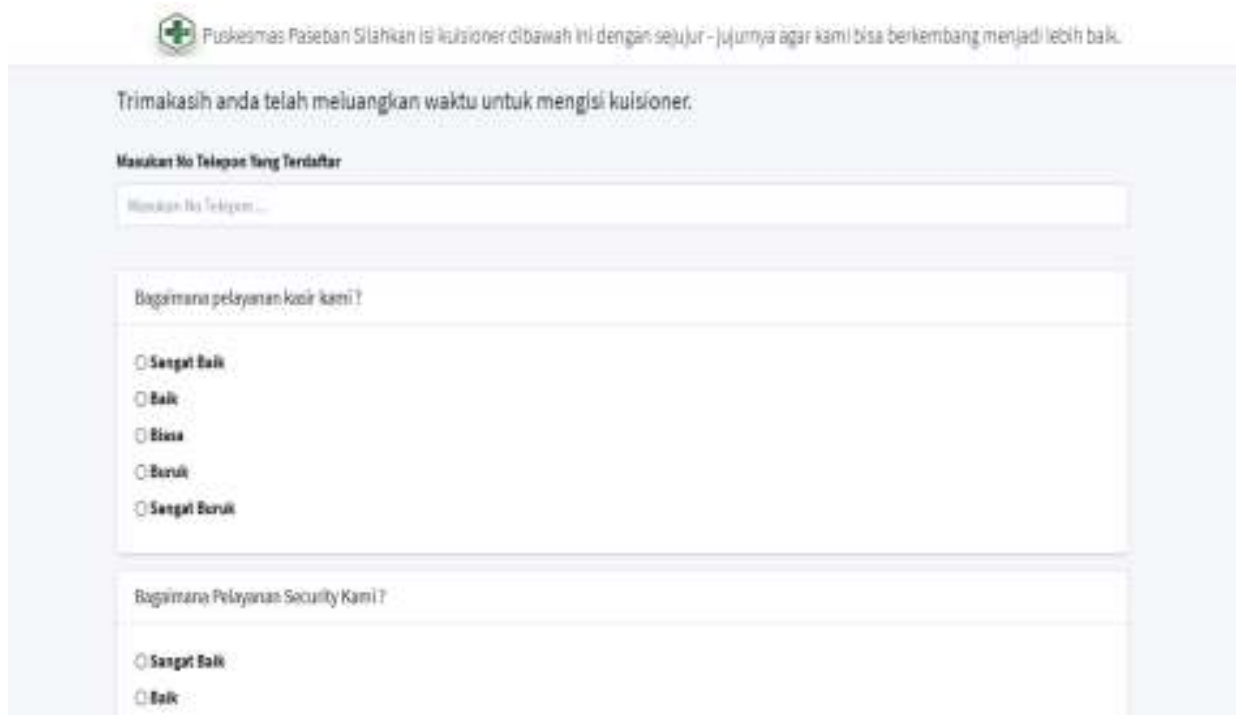

Gambar 15

Layout Mengisi Kuisioner

Berdasarkan gambar 15 terlihat layout mengisi kuisioner yang wajib di isi oleh pasien, didalamnya terdapa field yang wajib di isi oleh pasien.

\subsubsection{Layout Dashboard Admin}

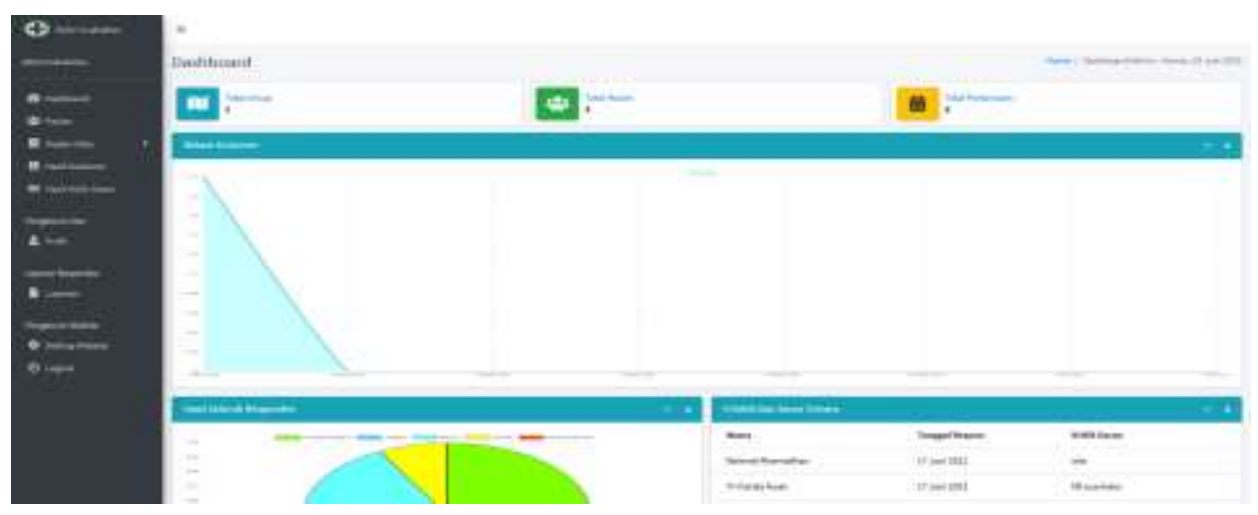

Gambar 16

Layout Dashboard Admin

Berdasarkan gambar 16 terlihat sebuah layout dashboard admin, halaman ini merupakan tampilan utam setelah admin berhasil login, didalam halaman ini admin dapat memiliki fitur manajemen yaitu : manajemen pasien, manajemen group, manajemen pertanyaan, manajemen hasil kuisioner dan manajemen laporan.

\section{cc) (1) (2)}

This work is licensed under a Creative Commons Attribution-NonCommercial-ShareAlike 4.0 International License. 


\subsubsection{Layout Master Pasien}

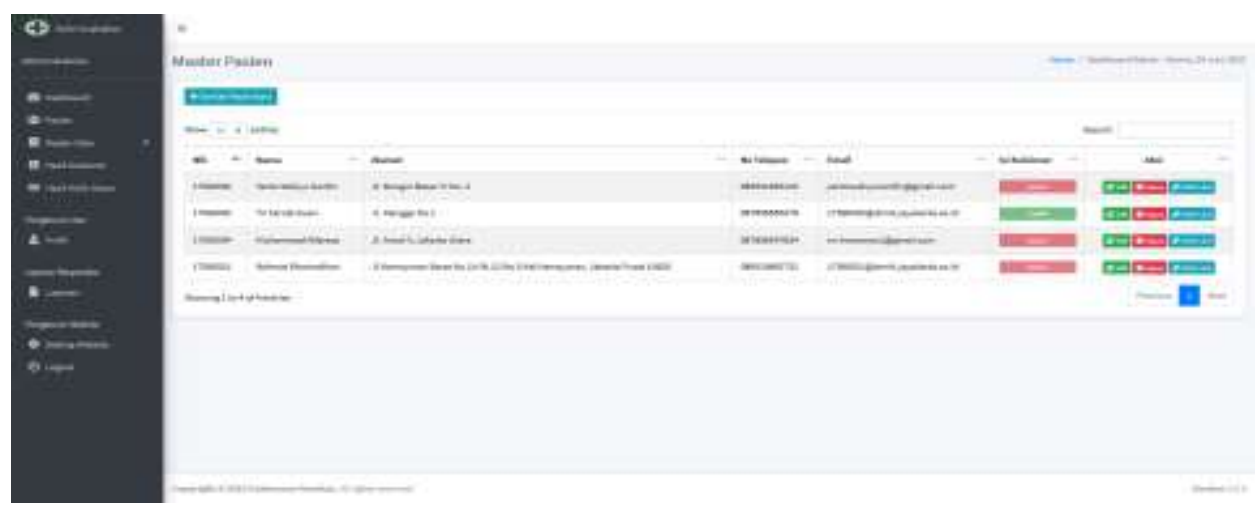

Gambar 17.

Layout Master Pasien

Berdasarkan gambar 17 terlihat sebuah layout master pasien, pada halaman ini berisi mengenai data pasien, didalam halaman ini, admin dapat melakukan manajemen data pasien serta mengirim link kuisioner kepada pasien.

\subsubsection{Layout Hasil Responden}

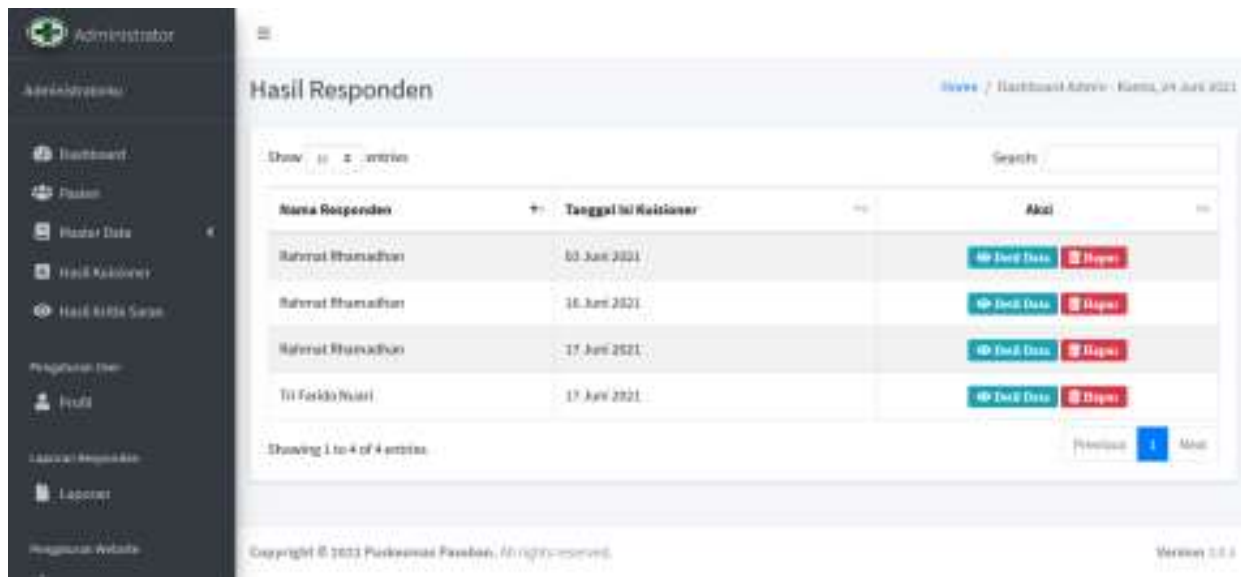

Gambar 18

Layout Hasil Responden

Berdasarkan gambar 18 terlihat sebuah layout hasil responden, didalam halaman ini berisi master data hasil responden, didalam halaman ini juga, admin dapat melihat dan menghapus data dari hasil responden

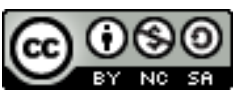

This work is licensed under a Creative Commons Attribution-NonCommercial-ShareAlike 4.0 International License. 
TRIDHARMADIMAS: Jurnal Pengabdian Kepada Masyarakat Jayakarta

http://journal.stmikjayakarta.ac.id/index.php/tridharmadimas

EmaiL: info@stmik.jayakarta.ac.id , tridharmadimas.jayakarta@gmail.com

DOI : $10.52362 /$ tridharmadimas.v1i2.648 /halaman : 86-101

E-ISSN: 2798-8295 (Online), P-ISSN: 2798-8554 (Print) Vol. 1, No.2, Desember 2021

\subsubsection{Layout Master Kuisioner}

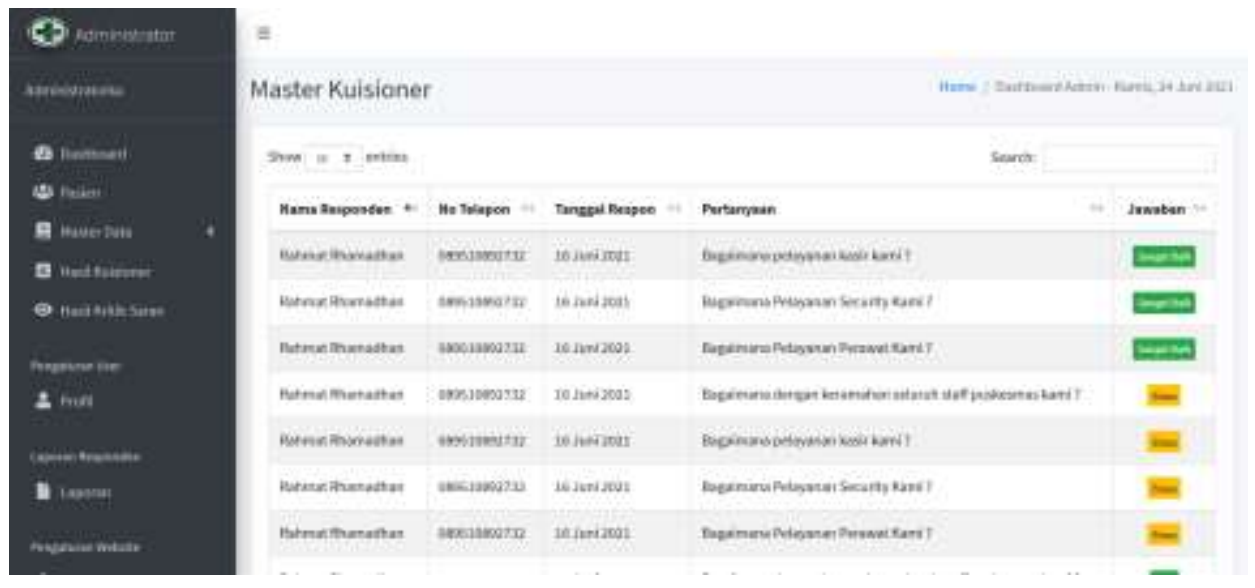

Gambar 19

Layout Master Kuisioner

Berdasarkan gambar 19 terlihat sebuah layout tampilan master hasil kuisioner. Didalam halaman ini berisi tentang hasil seluruh kuisioner yang telah di isi oleh pasien.

Uji coba dilakukan berdasarkan analisa permasalahan yang ada di puskesmas mengenai keluhan pasien sehingga dibuatlah aplikasi kuisioner keluhan pasien dengan tujuan dapat mempermudan pasien dalam memberikan keluhan serta kritik maupun saran demi kemajuan pelayanan puskesmas.Dibawah ini merupakan tahapan analisis yang dilakukan dalam melakukan penelitian di puskesmas, yaitu :

1. Pertama, menganasila permasalahan serta fakta yang terjadi di puskesmas mengenai keluhan pasien

2. Kedua, analisis desain serta coding, perancangan sistem mulai dari flowchart, uml, class diagram serta rancangan tampilan yang akan digunakan di sistem yang baru.

3. Ketiga, setelah sistem baru berhasil dibangun, selanjutnya masuk ke pengujian, hal ini bertujuan untuk mengetahu sejauhmana kefektifan sistem ini dan seberapa layak sistem ini untuk diterapkan dipuskesmas.

\section{KESIMPULAN.}

Setelah dilakukanya penelitian dalam pembuatan aplikasi keluhan pasien. Maka dapat disimpulkan sebagai berikut, yaitu :

1. Sistem ini akan memberikan notifikasi kepada pasien melalui sms dan email kepada pasien yang berisi link kuisioner.

2. Sistem ini dapat mempermudah pasien dalam mengisi keluhan pasien.

3. Sistem ini dapat mempermudah admin dalam membuat laporan hasil kuisioner perhari, perminggu, perbulan dan pertahun.

\section{REFERENSI.}

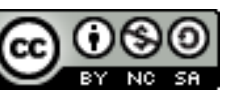

This work is licensed under a Creative Commons Attribution-NonCommercial-ShareAlike 4.0 International License. 
TRIDHARMADIMAS: Jurnal Pengabdian Kepada Masyarakat Jayakarta

http://journal.stmikjayakarta.ac.id/index.php/tridharmadimas

EmaiL: info@stmik.jayakarta.ac.id , tridharmadimas.jayakarta@gmail.com

DOI : 10.52362/tridharmadimas.v1i2.648 /halaman : 86-101

E-ISSN: 2798-8295 (Online), P-ISSN: 2798-8554 (Print) Vol. 1, No.2, Desember 2021

[1] Aandy. (2019). Pengertian XAMPP Lengkap dengan Fungsi dan Cara Instalasi. https:/qwords.com/blog/pengertian-xampp/

[2] Andre. (2021). Kuesioner adalah Instrumen untuk Mengumpulkan Data, Ketahui Jenis dan Kelebihannya. Merdeka.Com. Andre

[3] Ardiana, D. P. yudhi, \& Dwiputra, I. M. S. (2019). Sistem Informasi Penanganan Keluhan Pelanggan di Rumah Sakit Umum Surya Husadha Denpasar Berbasis Web. MATRIK : Jurnal Manajemen, Teknik Informatika Dan Rekayasa Komputer, 18(2), 257-267. https://doi.org/10.30812/matrik.v18i2.405

[4] Dermawan, M. I., Aknuranda, I., Hayuhardhika, W., \& Putra, N. (2019). Pengembangan Sistem Informasi Penanganan Keluhan Warga Desa Berbasis Web ( Studi Kasus Pemerintah Desa Suwayuwo ). Jurnal Pengembangan Teknologi Informasi Dan Ilmu Komputer, 3(2), 1557-1566. https://j-ptiik.ub.ac.id/index.php/j-ptiik/article/view/4504

[5] Fahrurozi, M. A., \& Masya, F. (2020). Keluhan Dan Kerusakan Berbasis Web Pada Pt Mitra. 5(1). https://jurnal.unimed.ac.id/2012/index.php/cess/article/view/15925/pdf

[6] Robith. (2020). Apa itu MySQL: Pengertian, Fungsi, beserta Kelebihan. Sekawan Media. https://www.sekawanmedia.co.id/pengertian-mysql/

[7] Zaman, S. N., Merlina, N., \& Nurajijah, N. (2021). Sistem Informasi Keluhan Pelanggan Berbasis Website. EVOLUSI : Jurnal Sains Dan Manajemen, 9(1). https://doi.org/10.31294/evolusi.v9i1.9636

This work is licensed under a Creative Commons Attribution-NonCommercial-ShareAlike 4.0 International License. 